\title{
Perceptions of cannabis among Humboldt County timberland and ranchland owners
}

\author{
A Humboldt County survey investigates traditional agriculturalists' views on cannabis cultivation.
}

by Yana Valachovic, Lenya Quinn-Davidson, Jeffery Stackhouse and Van Butsic

$\mathrm{H}$ umboldt County has been an epicenter of cannabis cultivation for decades, and an element of social division has characterized the region: the "back-to-the-landers" versus the born-and-raised locals, the "hippies" versus the "rednecks," and the pot growers versus the loggers and ranchers (Leeper 1990). However, as cannabis cultivation has been decriminalized in California, the social dynamics around cannabis have become more complex. Over the last 20 years, new growers from different parts of California, the United States and even outside the United States have moved to Humboldt County and surrounding areas to grow cannabis - a so-called green rush of growers hoping to strike it rich (Corva 2014). Growers have come from a host of countries beyond the United States, including Bulgaria, Russia, Mexico and nations in Southeast Asia (William Honsal, Humboldt County sheriff, personal communication; unreferenced). Some work independently while others work together in operations that may qualify as more organized. For many Humboldt County residents - "mom-and-pop" cannabis growers and more traditional agricultural producers alike - the near-exponential growth of the industry has been a shock, and it has unleashed numerous social, economic and environmental concerns.

\section{Abstract}

Cannabis is often grown on agricultural and forest lands in California, but little is known about the adjustments that traditional agriculture and timber producers are making to their livelihoods as cannabis becomes legal under state law. Our goal in this research was to better understand how larger landowners, whose families have often produced timber and cattle for generations, are experiencing increased cannabis production in their areas - and also to better understand these landowners' perceptions of the impacts of cannabis, whether positive or negative, on their communities. To accomplish this, we surveyed landowners who owned at least 500 acres in Humboldt County, an area that - more than 40 years ago - became one of the first California counties to begin experiencing expansive cannabis cultivation. Of the 211 landowners we invited to complete a survey, 71 responded, providing insights into their experiences with and perceptions of cannabis production. Many survey respondents reported illegal cultivation on their properties, problems with shared roads and other direct negative effects of cannabis production. Most landowners also reported that cannabis production has increased the cost of labor, though they acknowledge that it has increased the value of their property as well. Survey respondents, however, have not changed their views of cannabis with legalization. The findings of this study illustrate some of the challenges involved in developing land use ordinances and other policies that can support multiple industries whose interests may be in competition.

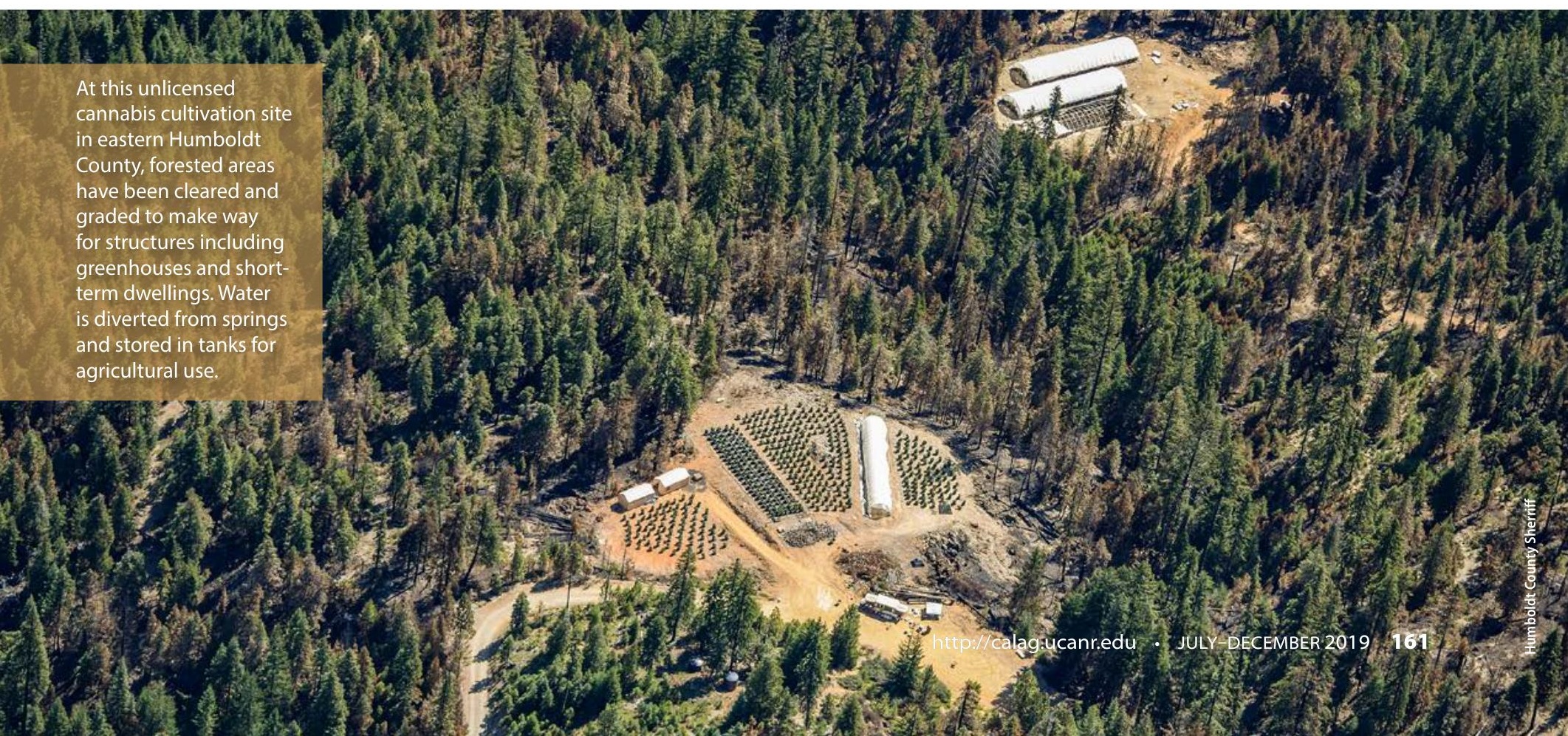




\section{California voters, when they legalized cannabis for adult recreational use in 2018, created conditions for competition among agricultural interests and changes in rural social dynamics.}

This situation is not unique to Humboldt - cannabis cultivation has increased rapidly throughout rural California (Butsic et al. 2018). California voters, when they legalized cannabis for adult recreational use in 2018, created conditions for competition among agricultural interests and changes in rural social dynamics. Indeed, because new cannabis farming is often conducted near traditional ranching and timber-producing lands (Butsic and Brenner 2016), the potential for conflict - or collaboration - between traditional land uses and cannabis production has grown. But little research documents the effects of cannabis production
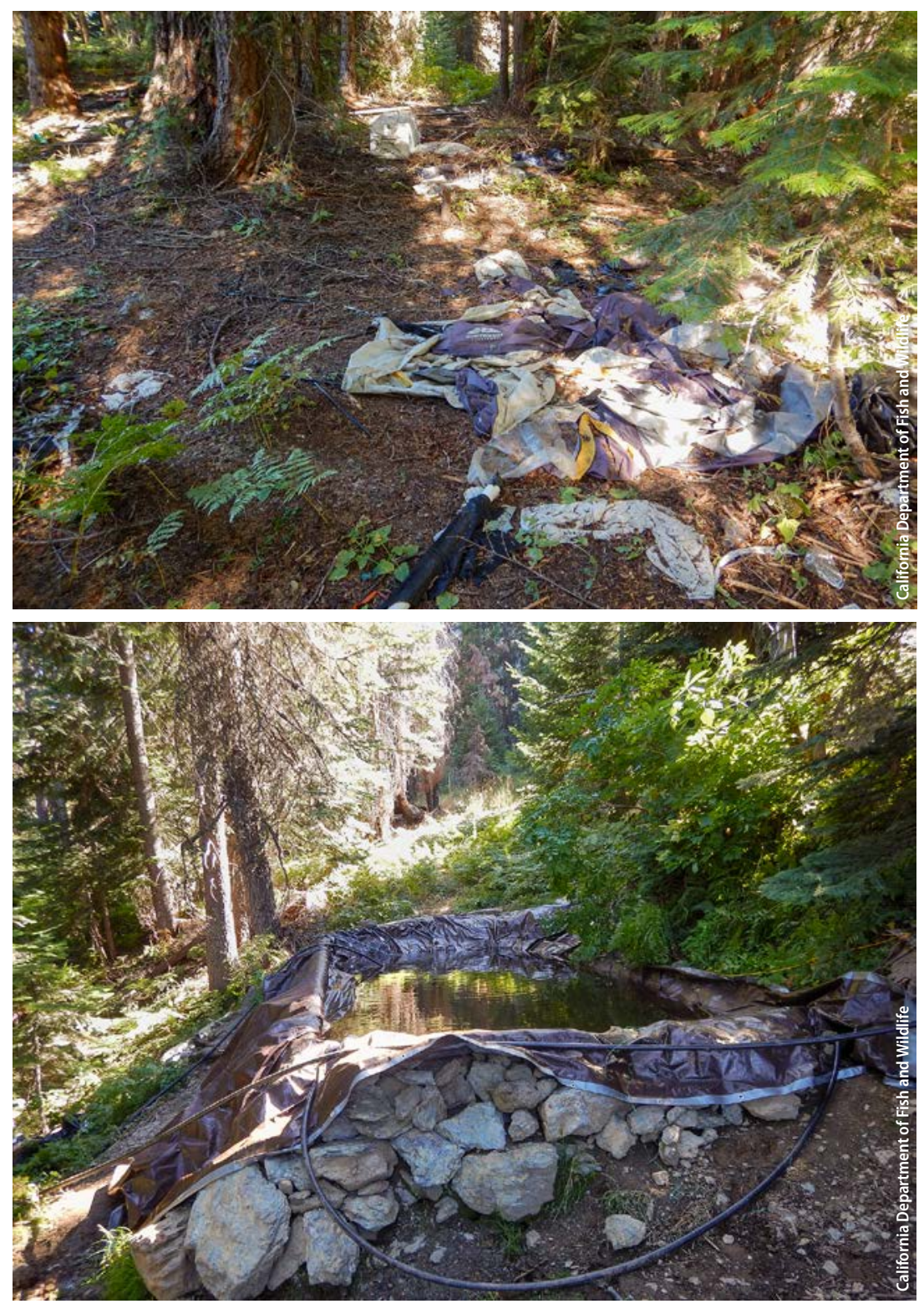

on traditional agricultural producers, and therefore we know little about such producers' adaptation to change. Understanding this dynamic is important for local governments as they develop land use policies to govern when, where and how much cannabis production is permissible (AIC 2017). Cannabis production's effects on neighbors is an important point for local government officials to consider as they develop and adopt new policies to encourage the transition of black-market cannabis operations into compliant operations. The effects of cannabis production on neighbors is also important to consider while formulating policies to mitigate unintended consequences - such as unwanted odors and nighttime lights - which can exacerbate land use and social conflicts. For example, should cannabis be allowed on lands zoned for timber production or prime agriculture? Should cannabis production be allowed in cities and in unincorporated towns? What areas are compatible or incompatible with cannabis?

Increased cannabis production can directly or indirectly affect traditional agriculture and timber producers. Over the last decade, cannabis cultivation has expanded rapidly in rural communities, with many cannabis farmers having moved only recently to the areas where they grow (Polson 2015). These new arrivals are sometimes described as green rush growers. Conflicts can arise if new growers, who are often unaware of community norms, don't manage workers appropriately, control dogs, close gates, help maintain shared roads (private dirt roads that facilitate access to multiple parcels, with landowners providing their own maintenance and upkeep) - or if, in other ways, they complicate operations for traditional agricultural producers. Likewise, even cannabis producers who have been in business for many years - including some whose families have grown cannabis for two generations - may hold different views of rural life than do traditional agriculture and timber producers (Polson 2017). In addition, while cannabis is now legal in California, many cannabis farmers still grow outside the regulated system, and some traditional agricultural producers may retain the sense that illegal activity is negatively affecting their community. In recent years, the environmental impacts of cannabis cultivation have been a matter of increasing focus in California, and traditional agricultural producers and other community members have voiced concerns about water diversions (Bauer et al. 2015), pollution from chemical fertilizers (Carah et al. 2015), the impacts of pesticides on wildlife (Gabriel et al. 2015), light pollution (Stansberry 2016a) and forest fragmentation (Wang et al. 2017). Concerns have also arisen regarding negative impacts on local

Top, materials from a trespass grow that were left on a neighbor's property. Bottom, an example of water theft, in which growers on private land trespass onto a neighbor's property to find water, which can be in limited supply in this region. 
livestock producers (Ramirez 2016; Sims 2016; Walker 2017) and challenges for public land managers attempting to control trespass growing operations (Rose et al. 2016).

At the same time, cannabis cultivation can contribute to community well-being in a variety of ways. It can bring economic gains to rural areas (Polson 2013) where the timber, livestock and fisheries industries have experienced declines. For example, cannabis cultivation can provide new business opportunities to traditional agricultural producers in the form of heavy equipment work, firewood sales, trucking, forest management or construction services. In addition, cannabis production may help buffer population declines such as those experienced in many of California's rural areas over the last 20 years; in particular, rural schools may benefit from the enrollment of cannabis growers' children. More broadly, cannabis farmers can bring new energy to rural communities through engagement at schools, volunteer fire departments and other points of gathering.

Traditional growers' perceptions of cannabis farmers can vary based on several factors, including the scale at which cannabis farmers operate. Scales of operation have expanded greatly over the last 20 years. Some cannabis farmers produce a few plants for personal use, others augment their incomes by growing moderate amounts of cannabis and still others grow on an industrial scale, with multiple operations on numerous parcels. All scales of operation include both regulatory-compliant growers and black-market growers. One might expect traditional agricultural producers to regard these different varieties of cannabis growers differently. But large landowners are themselves not homogenous - for example, some are absentees. In this research we hypothesized that absentee landowners would have different experiences and perceptions of the cannabis industry than do traditional producers who live on their land.

Humboldt County and many communities around California are currently setting ordinances to manage legal cannabis production. But as they do so, little is known about the potential interaction of cannabis with traditional agriculture and timber producers and whether these industries are compatible. Information about the effects of cannabis production on traditional agricultural producers may be helpful to policy makers because traditional producers are often important contributors to rural economies and stewards of publictrust resources such as wildlife and clean water. We conducted this research with the goal of determining how larger landowners - who, in Humboldt County, are generally timber or beef producers - experience and perceive cannabis production. We surveyed by mail all landowners in Humboldt County who own at least 500 acres $(n=211)$. We asked a series of questions about landowner experiences with the cannabis industry and how the industry directly affected landowners' economic well-being, community, property and personal safety. We also asked how, in their view, the cannabis industry influences the community and the environment. We asked landowners to provide their views on grower demographics and on changes in their communities over time. In addition, we compared the experiences and perceptions of absentee and nonabsentee landowners.

\section{Study area}

Humboldt County has long been among the leading cannabis-producing regions in the United States (Corva 2014). Located on the North Coast of California, Humboldt County is characterized by steep terrain and a Mediterranean climate; a climatic gradient runs from the cooler and wetter coastline to the drier and warmer inlands (State of California 2015). Humboldt County's agricultural and timber industries are significant in scale, with agricultural production amounting to $\$ 326$ million in 2016 (including \$99 million in livestock) and timber production amounting to $\$ 70$ million in the same year (Humboldt County 2016) - although the timber numbers are down from a decade ago. These agricultural production numbers do not include cannabis production revenues, but recent estimates put cannabis production in the larger Humboldt, Trinity and Mendocino region, known as the "Emerald Triangle," at $\$ 5$ billion annually (Macewan et al. 2017).

Humboldt County is home to numerous species of concern - including threatened and endangered salmonids, spotted owls, marbled murrelets, fishers and so on - that are protected under the U.S. Endangered Species Act (Mooney and Zavaleta 2016). Cannabis cultivation occurs within these species' habitat areas, including in locations near and adjacent to old-growth redwood and Douglas fir forests.

\section{Survey methodology}

The intent of the survey was to understand how cannabis production in Humboldt County was affecting traditional agricultural producers, and therefore we focused only on landowners with enough property (at 
least 500 acres) to derive a large percentage of their income from agriculture and timber activities. We identified landowners with at least 500 acres by combining land use and tax roll data. In total, 211 landowners fit this description.

Landowners were mailed a paper survey, along with a stamped, pre-addressed envelope in which to return it, in January 2018. After 3 weeks, follow-up postcards were sent to landowners who had not returned their surveys. In total, 71 landowners responded to the survey (a response rate of 34\%). Of these, two landowners reported owning less than 500 acres and one landowner did not confirm meeting this minimum standard; we did not include these three surveys in our analysis. All survey responses were anonymous.

\section{Survey organization}

Surveys were organized into three sections. One portion of the survey asked landowners about their direct experiences with the cannabis industry, asking them to agree or disagree with 22 statements that corresponded to four themes: (1) how the cannabis industry has affected the economics of their operations (five statements); (2) how cannabis has impacted their local community (five statements); (3) how cannabis has affected their properties (eight statements) and (4) how cannabis has affected their safety (four statements). The surveys asked landowners to respond to each statement using a five-point Likert scale, with responses ranging from strong disagreement (one point) to strong agreement (five points). Respondents could also respond "NA" to statements that did not apply to them. Additionally, respondents were given space at the end of each subsection to provide comments or examples.

In another section of the survey, we tested respondents' perceptions of cannabis by asking them how they felt about certain cannabis-related issues and whether cannabis cultivation has had positive or negative impacts on their communities, specifying that their responses should not necessarily be based on their personal experiences. We provided 36 statements that corresponded to four themes: (1) community (13 statements); (2) the environment (seven statements); (3) changes over time in property values, community safety, community demographics and so on (nine statements) and (4) grower demographics (seven statements). Respondents were asked to agree or disagree with the statements using a 5-point Likert scale and were able to provide comments after each subsection.

The third section of the survey solicited background information about each respondent. Respondents were asked whether they earned income from timber, ranching or dairying, how long their families had owned the land they worked and whether they were absentees. In addition, we asked landowners if they had been approached about selling their land for cannabis cultivation (and if so, when) and if they had next-generation succession plans for the family ranch or timber business. We also asked if landowners knew of nearby cannabis growing.

\section{Analysis}

All data from the survey was entered into spreadsheets by hand and then imported into Stata statistical software. For each statement, we created histograms of the Likert-scale responses (1-5) to understand the experiences and perceptions of respondents. We used a two-sample t-test to compare differences in responses between absentee and non-absentee landowners.

\section{Landowner background}

As indicated previously, all respondents included in our survey owned at least 500 acres of land. Twentytwo percent owned between 500 and 1,000 acres, 51\% owned between 1,000 and 5,000 acres and $28 \%$ owned more than 5,000 acres. Of the 69 landowners whose responses were included in our results, 63 respondents managed timberland and 56 respondents managed ranchland, meaning that most respondents managed both land types; only one respondent was involved in dairy farming. Forty-six percent of respondents lived on their properties full time, while $20 \%$ lived on their properties part time. Thirty-three percent of respondents were absentee landowners. In general, the land represented in the survey had been in respondents' families for a long time - more than 50 years in $81 \%$ of the cases, 25 to 50 years in another $10 \%$ of the cases, less than 25 years in $6 \%$ and less than 5 years in only $3 \%$ of the cases. Fifty percent of respondents reported that their primary income was from traditional forms of agriculture or timber production; no respondents reported cannabis as their primary income source.

\section{Landowner experiences}

\section{Economics}

Seventy-one percent of landowners reported that they did not grow cannabis on their property while $18 \%$ reported that they did. These percentages, however, are derived only from the 34 of 69 respondents who agreed or disagreed with the statement that they had used their property to grow cannabis. The remaining respondents - half the total - chose not to indicate whether they had grown cannabis, potentially indicating landowners' reluctance to associate themselves with the cannabis industry. About $40 \%$ of respondents had indirectly profited from cannabis through off-farm work such as heavy equipment work, trucking and so on (fig. 1). Fifty-seven percent of all respondents agreed or strongly agreed with the statement that "the cannabis industry has negatively affected my livestock operations," while $27 \%$ disagreed with this statement. Over $60 \%$ of respondents agreed that cannabis had increased the cost of labor. Comments that respondents offered on the cost of labor included "Property values 
are inflated by the cannabis industry, hence costing us more for leases and ownership."

\section{Community effects}

Seventy-five percent of respondents agreed or strongly agreed with the statement that "shared roads have been degraded by cannabis growers" (fig. 2) and 65\% agreed that noise pollution has increased due to cannabis growing. Fifty-five percent of respondents agreed that growers increase light pollution and $71 \%$ reported having experienced illegal garbage dumping by cannabis growers on or near their property. Forty percent of landowners disagreed or strongly disagreed with the statement that "I know growers who have values that align with my own" (fig. 1). At the same time, 34\% of respondents agreed or strongly agreed with that statement (fig.1). One respondent added that " $[\mathrm{M}]$ onetary impact is obvious. Cultural and moral impacts are terrible."

\section{Property}

Fifty-six percent of respondents agreed or strongly agreed that water sources have been impacted by cannabis growers, while $25 \%$ disagreed with this statement. Fifty-six percent also agreed that water had been stolen from their property. Seventy-two percent of respondents had experienced trespassing, while $20 \%$ had not. Forty percent of respondents reported that their fencing or infrastructure had been destroyed by cannabis growers, though a similar percentage had not. Fifty percent of landowners reported that neighboring growers had failed to assist with fence maintenance, and $75 \%$ of landowners reported having discovered trespass grows on their property (fig. 2). One respondent added that "[Growers'] dogs killed our cattle. My brother confronted a grower in fatigues carrying an assault rifle on our property. [Our] fences have been wrecked, roads damaged, and stream water theft." Another respondent wrote that "Yes, this is true in the past, but with the pot market collapsing I don't think this will be a problem in the future".

\section{Safety}

Roughly 55\% of landowners reported having been threatened by cannabis growers' dogs while $24 \%$ did not. Forty-six percent of landowners reported that their safety had been threatened by growers. Equal proportions of landowners reported, and did not report, having felt unsafe due to interactions with growers on public lands. Finally, 50\% of landowners agreed that growers had committed crimes against them or their property.

\section{Landowner perceptions}

\section{Community effects}

Perceptions of cannabis growers were relatively unified among survey respondents. A majority of respondents (78\%) did not perceive growers as having values similar to their own (fig. 3). The majority of landowners (77\%) felt that growers had changed how it feels to live in their community (fig. 3), and $77 \%$ of landowners expressed concern about the changes that growers are bringing to their community. More than $80 \%$ of respondents were concerned about growers taking over working lands

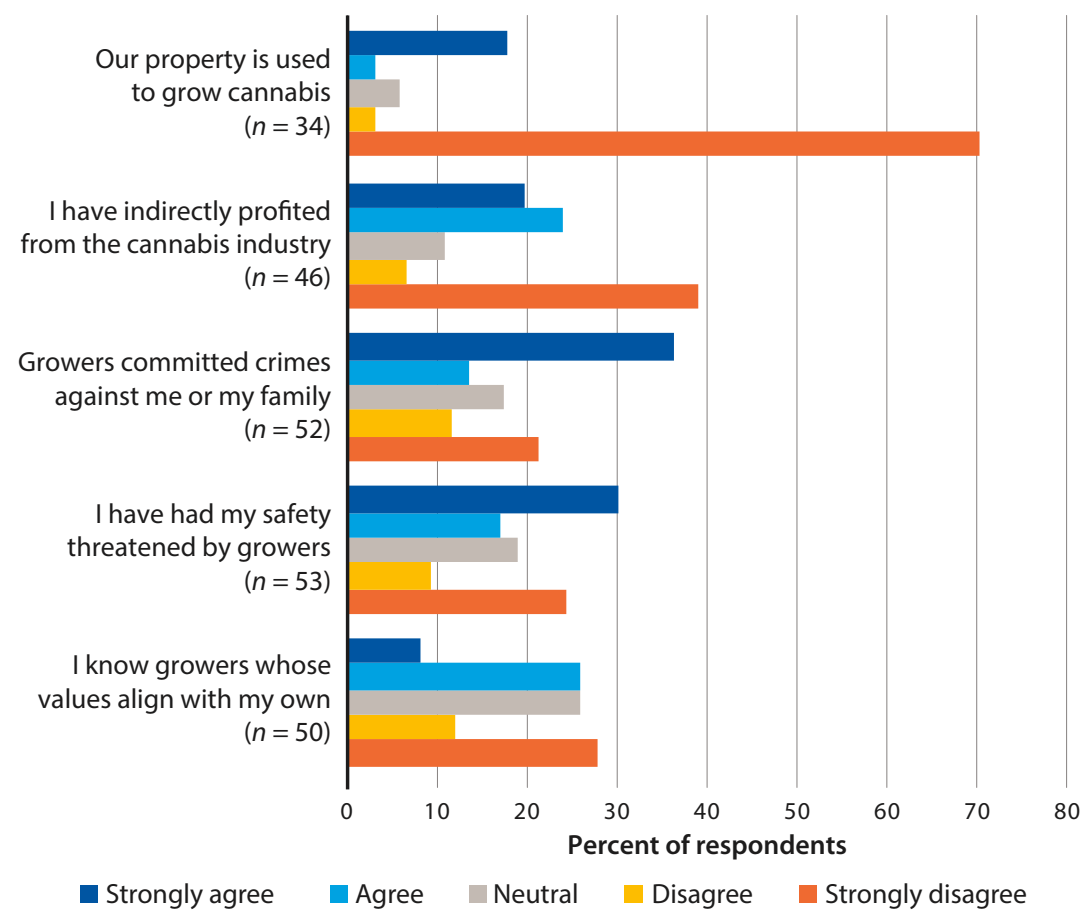

FIG. 1. Survey respondents reported their direct experiences with cannabis. Not all respondents were comfortable sharing personal information - of 69 respondents who returned surveys, only 46 indicated whether they had indirectly profited from the cannabis industry and only 34 responded to a question about growing cannabis on their properties.

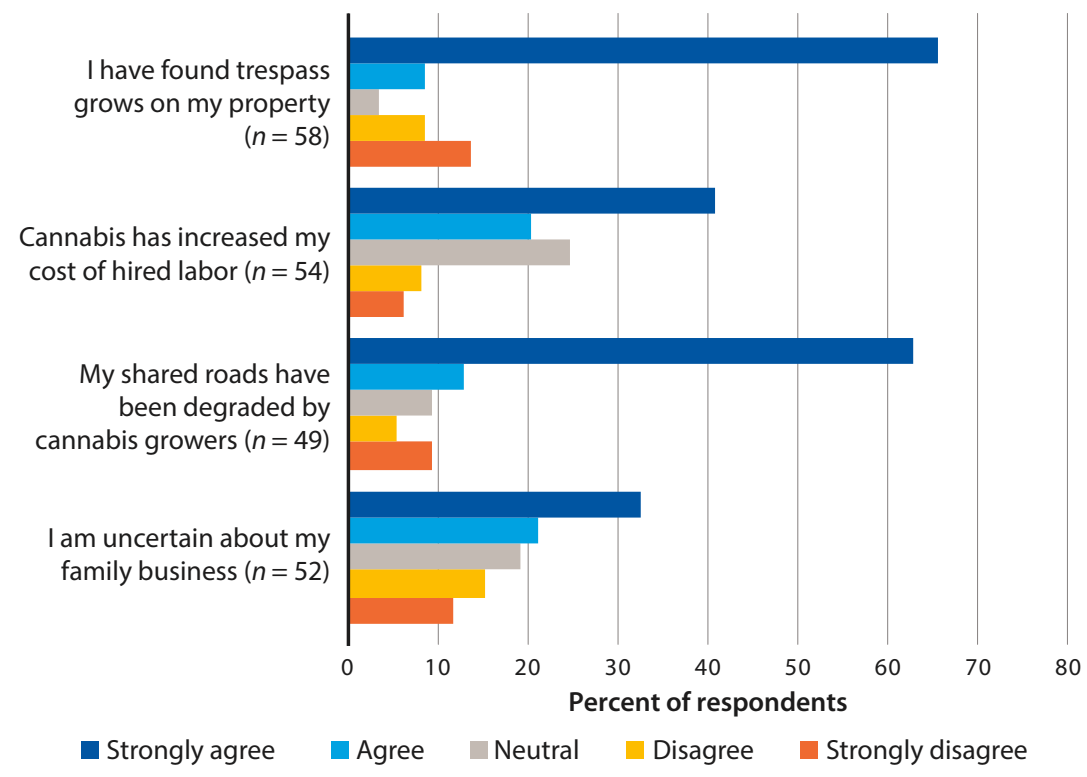

FIG. 2. Survey respondents have experienced direct negative impacts related to neighboring cannabis production and express concern for the future of their family businesses. 
in their communities, and the same percentage were concerned that growers reduce the influence in the community of timber managers and ranchers. One respondent wrote that "The bottom line is that our family would accept the negative economic impact of eliminating 'pot' in return for the elimination of all the negative impacts of the grower culture." More than $90 \%$ of respondents agreed that growers from urban locations do not understand rural land management. Most landowners $(60 \%)$ disagreed that growers are reinvigorating their rural communities or that growers are the only

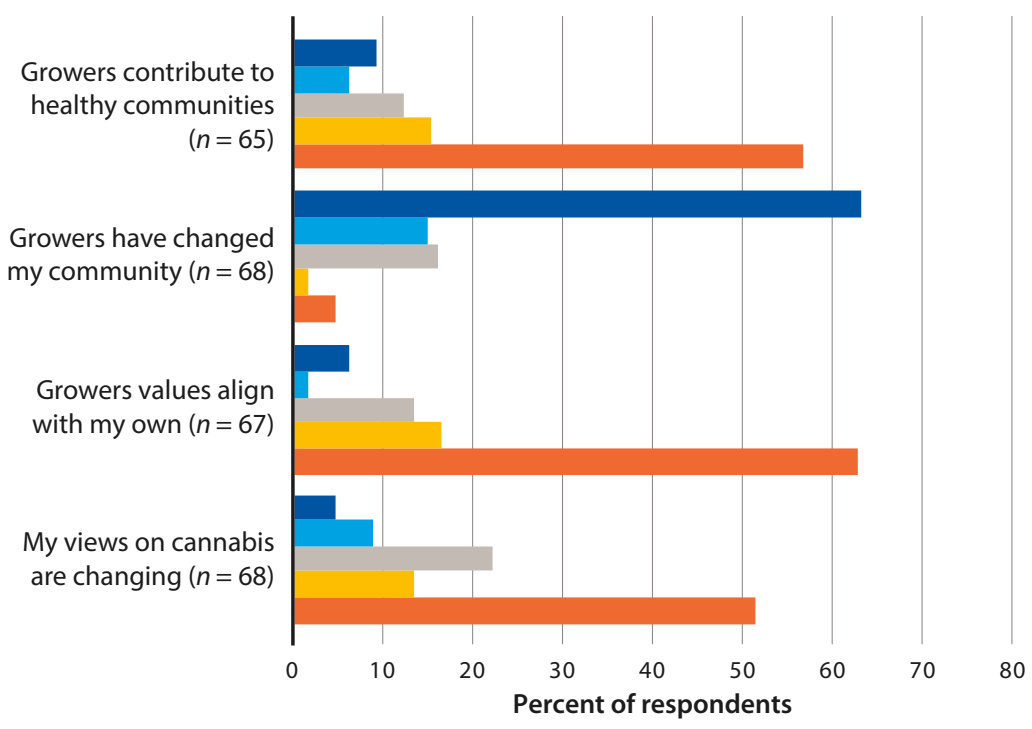

- Strongly agree $\square$ Agree $\square$ Neutral $\square$ Disagree $\square$ Strongly disagree

FIG. 3. Survey respondents' reported perceptions indicate that their views of cannabis have not changed and suggest a generally negative view of cannabis growers' contributions to the local community.

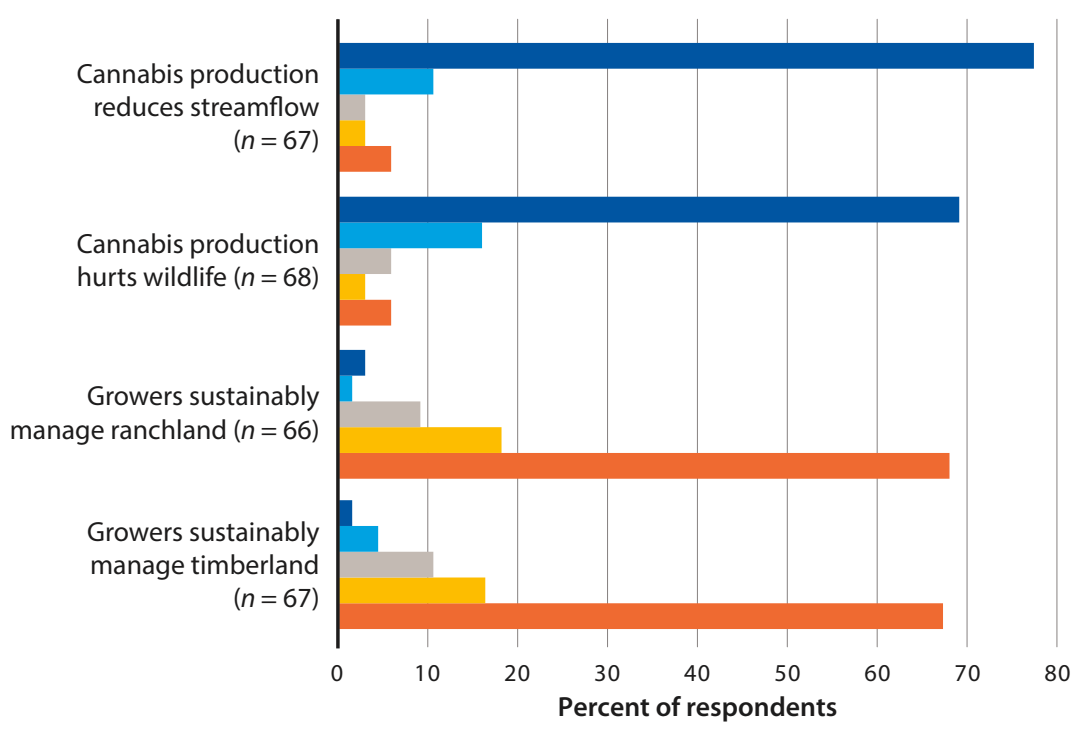

- Strongly agree $\square$ Agree $\square$ Neutral $\square$ Disagree $\square$ Strongly disagree

FIG. 4. Survey respondents reported their generally negative perceptions of cannabis growers' environmental stewardship and identified environmental impacts of cannabis growing. thing keeping their communities going (60\%). Eightythree percent of respondents disagreed with the statement that growers do a good job of policing themselves. Most landowners (64\%) have not changed their views on cannabis with medical or recreational legalization (fig. 3).

\section{Environment}

The clear majority of respondents (84\%) did not think cannabis growers manage timberlands sustainably (fig. 4) and a similar percentage (86\%) felt the same about ranchlands. Eighty-five percent of respondents regarded cannabis growing as negatively affecting wildlife and $87 \%$ regarded it as negatively affecting stream flow (fig. 4). Eighty-four percent thought cannabis growing leads to soil erosion and $70 \%$ thought it increases fire hazard. Seventy-eight percent believed that cannabis production in ranchlands and timberlands leads to habitat fragmentation and the same percentage suggested that the economic value of cannabis incentivizes the subdivision of large parcels.

\section{Changes over time}

Fifty percent of landowners felt that their property value had increased due to cannabis production while $40 \%$ were neutral on that question. Eighty-three percent of respondents thought that Humboldt County was a safer place before cannabis and $76 \%$ of respondents perceived new cannabis growers as less responsible than cannabis growers who have been in the county for years. About half of respondents (51\%) believed that increased cannabis legalization will be good for Humboldt County. Fifty-seven percent of respondents were not yet willing to accept that cannabis is a leading industry and that people should support it. Fifty-four percent of respondents believed that Humboldt County would be better off in the future without cannabis.

\section{Grower demographics}

Most landowners (80\%) included in the survey reported having observed changes in grower demographics in the last decade. Most (57\%) felt that the number of small cannabis growers is decreasing. Sixty-one percent felt that the number connected to organized crime is increasing and perceived that there is an increasing number of green rush growers (83\%) in their communities. Most respondents (76\%) were concerned about organized crime, while only $48 \%$ were concerned with green rush growers and $18 \%$ with small growers.

\section{Comparison of resident and absentee owners}

Overall, resident and absentee owners expressed similar views on most issues. Of the survey's 59 statements on experiences and perceptions, statistically significant differences between the two groups appeared for only eight statements. Absentee owners were more likely to report that their surface water resources had been 
impacted by growers; that their fences or infrastructure had been destroyed by growers; that their safety had been threatened by growers and that they had been threatened by growers on public land. Absentee owners were also more likely to be concerned that growers were taking over public land. They were less likely to agree that growers manage timberland sustainably and that cannabis production decreases their property values.

\section{Environmental, social and economic challenges}

With this study, we aimed to better understand the experiences and perceptions of traditional agricultural producers - the families who, in most cases for several generations, have made a living off their land, all the while watching changes occur in the social, economic and environmental dynamics that surround cannabis.

This survey's documentation of social tensions may not come as a surprise to those who have lived in Humboldt County (note that three of the authors live in the county and thus have a personal vantage point on the issues). Even after many decades of cannabis cultivation, traditional agricultural producers have not warmed to the people or practices involved in the cannabis industry. Indeed, changes in the social fabric of the cannabis industry have only perpetuated and intensified existing tensions.

As this survey shows, concerns about "small growers" are minimal now - those growers have become part of the community, and one-third of respondents agreed that they know growers whose values align with their own. What was novel 40 years ago is now a cultural norm. Today's concerns center instead on the challenges of current cannabis culture: environmental degradation and the threat of major social and economic change. Respondents mostly agreed that growers today are less reasonable than those who have been in the county for many years. As one respondent wrote, "Growers are a cancer on Humboldt County." This distrust highlights the challenges that, in rural areas, can often hinder community-building and mutual assistance mechanisms, which are often needed in isolated communities (Morzillo et al. 2015).

The economic influence of cannabis can be seen throughout the county. As the survey shows, approximately $40 \%$ of respondents have been impacted indirectly by the cannabis industry, and some respondents have directly profited through cannabis production themselves. Interestingly, just over half the respondents chose not to say whether they grow cannabis, hinting at the possibility that, even for traditional agricultural producers, cannabis has presented an opportunity to supplement income and cover the costs of landownership. However, the broader economic growth attributed to the cannabis industry is not always viewed favorably, and a majority of respondents agreed that Humboldt County would be better off in the future without cannabis. Some respondents claimed that the industry has increased the cost of labor and that, in many cases, it can be difficult to find laborers at all because the work force has been absorbed by higher-paying cannabis operations. Likewise, many respondents agreed that land values have increased because of cannabis. But for landowners whose property has been passed down through generations, and who have little intention of selling, increased land values translate into increased taxes and difficulty in expanding operations, both of which can be limiting for families who are often land-rich but cash-poor. One respondent wrote, "Yes, the price of land has gone up... but this is a negative. It increases the inheritance tax burden, and it has become so expensive that my own adult children cannot afford to live here." In Humboldt County's unique economic climate, it's difficult for most landowners to decide whether the opportunities the cannabis industry provides are worth the toll that they believe the industry takes on their culture and community - it's not a simple story. As one respondent noted, "If I had taken this survey 40 years ago, my response would have been very different. With Humboldt County's poor economy, everyone is relying on the cannabis industry in one way or another." Our survey provides an important baseline from which such changing attitudes can be measured.

Our results should be seen in the context of larger trends involving population and agricultural land in Humboldt County. At the time we were preparing our survey, property records indicated that slightly more than 200 landowners in the county owned at least 500 acres; these individuals made up our survey population. Past research, however, has documented that cannabis was likely grown on over 5,000 distinct parcels (of smaller sizes) in Humboldt County in 2016 (Butsic et al. 2018). Our survey respondents, because of their large holdings, may be unusually exposed to cannabis growers physically because their larger properties may have more contact with cannabis growers. At the same time, these respondents might be better able to survive economically in a Humboldt County without cannabis. It is unclear if the experiences and perspectives of many Humboldt County smaller landowners would be similar to those of these large landowners.

For many in Humboldt County, the impacts of cannabis production on property and the environment are a central concern. Respondents mentioned problems involving shared roads and fences, illegal garbage dumping and contamination, deforestation, fire hazards, feral dogs and impacts on wildlife and domestic livestock. One respondent wrote that "Growers leave a mess, steal water, tear up roads, let guard dogs damage neighbors' property, including livestock, poison wildlife, increase soil erosion and threaten people." In many ways, it seems that land ethics are at the center of the concerns that traditional agricultural producers harbor about the new wave of cannabis growers.

Though respondents remarked on cannabis growing's direct impacts on the environment, they also largely agreed that the cannabis industry is causing fewer young people to enter traditional farming careers - and that growers are taking over working lands. It is unknown if the rates at which successive generations stay in the family business are lower in Humboldt County than in rural communities less influenced by cannabis. For families who have managed and lived off these lands for decades - most of them for more than 50 years these shifting stewardship ethics threaten their immediate environment as well as their very identity.

\section{Conclusion}

The cannabis industry is undergoing drastic changes throughout California and elsewhere in the United States. In many places, the cannabis industry is novel, and social and environmental ethics are developing in concert with the growth of the industry. Humboldt County, in contrast, has been on the leading edge of cannabis cultivation for decades. County residents have watched the industry grow and change substantially over the years, with varying impacts on the culture and economy of the region (Stansberry 2016b). The mixed blessings of cannabis are not lost on most who live in Humboldt County: Over the last several decades, cannabis has breathed life into many of the smaller communities that had suffered losses in timber 
and other industries, and this boon has been palpable in the more populated parts of the county, too. However, the pace of change in the cannabis industry has been very quick, and the pressures that the industry exerts on communities are intense. Few have felt these pressures more than the county's traditional agricultural producers, whose communities, livelihoods and landscapes have been most affected.

It is not clear how recent and future changes to cannabis law will change social and economic conditions in Humboldt County, but this survey helps describe the competing interests at stake in the evolution of Humboldt County's agricultural identity. For the longtime Humboldt landowners included in our survey, the consistent pressure exerted by the cannabis industry over the last 40 years has forced them to define - and sometimes redefine - their values and alliances. This survey shows that, as the cannabis industry has expanded, traditional agricultural producers have felt an increased pull toward the ethics of stewardship, community and family identity. However, the stark lines that once separated cannabis growers from farmers and ranchers are not so clear now, and there is a shared curiosity and concern in the county about the next wave of change in cannabis cultivation: How will small versus large operations capitalize on legalization? How will compliant growers and black-market growers compete in this new era? How will the values that have long defined Humboldt County's agricultural lands - community, a locally based economy, working lands and working families - maintain a place among so much change? And how will public policy makers mediate the challenges? This study helps document how the last 40 years of cannabis production have largely been incompatible with ranch and timber operations. Public land use policy can help mediate land use conflicts and zoning, but it will not be able to mediate all social behaviors and industry needs. The survival of rural economies is dependent on balancing support for new economic opportunities with supporting the needs of multigenerational industries. Success will be measured by the persistence, environmental health and economic prosperity of rural communities. CA

Y. Valachovic is UC Cooperative Extension (UCCE) Forest Advisor and Humboldt-Del Norte County Director; L. Quinn-Davidson is UCCE Area Fire Advisor (Trinity, Siskiyou, Mendocino and Humboldt counties); J. Stackhouse is UCCE Humboldt-Del Norte County Livestock and Natural Resource Advisor; and V. Butsic is UCCE Assistant Specialist, Department of Environmental Science, Policy, and Management, UC Berkeley.

We would like to thank Humboldt County private landowners for their participation; Jennifer Steenblock for her assistance; numerous Humboldt County department heads for survey input and recent Buckeye Conservancy Executive Director Lauren Sizemore for guidance.

\section{References}

[AIC] University of California Agricultural Issues Center. 2017. Economic Costs and Benefits of Proposed Regulations for the Implementation of the Medical Cannabis Regulation and Safety Act (MCRSA). www.dof. ca.gov/Forecasting/Economics/ Major_Regulations/Major Regulations_Table/documents/ SRIAandAppendix.2.28.17.pdf

Bauer S, Olson J, Cockrill A, et al. 2015. Impacts of surface water diversions for marijuana cultivation on aquatic habitat in four northwestern California watersheds. PLOS ONE 10(3):e0120016. https:// doi.org/10.1371/journal. pone.0120016

Butsic V, Brenner JC. 2016. Cannabis (Cannabis Sativa or C. indica) agriculture and the environment: A systematic, spatially-explicit survey and potential impacts. Environ Res Lett 11(4):044023. https://iopscience. iop.org/article/10.1088/17489326/11/4/044023/meta

Butsic V, Carah JK, Baumann M et al. 2018. The emergence of cannabis agriculture frontiers as environmental threats. Environ Res Lett 13(12):124017.

https://iopscience.iop

org/10.1088/1748-9326/ aaeade/pdf
Carah JK, Howard JK, Thompson SE, et al. 2015. High time for conservation: Adding the environment to the debate on marijuana liberalization. BioScience 65(8):822-9. https://doi. org/10.1093/biosci/biv083

Corva D. 2014. Requiem for a CAMP: The life and death of a domestic US drug war institution. Int J Drug Policy 25(1):7180. https://doi.org/10.1016/j. drugpo.2013.02.003

Gabriel MW, Woods LW, Wengert GM, et al. 2015. Patterns of natural and humancaused mortality factors of a rare forest carnivore, the fisher (pekania pennanti) in California. PLOS ONE 10(11):e0140640. https://doi.org/10.1371/journal. pone.0140640

Humboldt County. 2016 Humboldt County Department of Agriculture/Weights and Measures 2016 Crop Report. https://humboldtgov.org/DocumentCenter/View/61579/2016CROP-REPORT? bidld =

Leeper JS. 1990. Humboldt County: Its role in the Emerald Triangle. Calif Geogr Soc 100:93-109. http:// scholarworks.csun.edu/handle/10211.2/2609
Macewan D, Newman C, Howitt R, Noel J. 2017. Economic Impact Analysis of Medical Cannabis Cultivation Program Regulations. Report prepared for California Department of Food and Agriculture. www.dof. ca.gov/Forecasting/Economics/ Major_Regulations/

Major_Regulations_Table/ documents/20170203Final MCCPSRIA.pdf

Mooney HA, Zavaleta E (eds.) 2016. Ecosystems of California. Berkeley: University of California Press. www.ucpress. edu/book/9780520278806/ ecosystems-of-california

Morzillo AT, Colocousis CR, Munroe DK, et al. 2015. "Communities in the middle": Interactions between drivers of change and place-based characteristics in rural forest-based commu-

nities. J Rural Stud 42:79-90.

https://doi.org/10.1016/j jrurstud.2015.09.007

Polson M. 2013. Land and law in marijuana country: Clean capital, dirty money and the drug war's rentier nexus. Polar-Polit Leg Anth 36(2):215-30. https:// doi.org/10.1111/plar.12023
Polson M. 2015. From outlaw to citizen: Police power, property and the territorial politics of medical marijuana in California's exurbs. Territory Polit Gov 3(4):387-406. www.tandfonline. com/doi/abs/10.1080/216226

71.2015.1073613?journalCode =rtep20

Polson M. 2017. Planning for marijuana: Development, governance and regional political economy. In The Illicit and Illegal in Regional and Urban Governance and Development: Corrupt Places. Chiodelli F, Hall T, Hudson R (eds.). New York: Routledge. Chapter 9

Ramirez L. 2016. Ranchers fed up with dogs attacking livestock. KRCR News Channel 7. Mar. 9. https://krcrtv. com/archive/ranchers-fedup-with-dogs-attackinglivestock_20160513210902160

Rose J, Brownlee MTJ, Bricke KS. 2016. Managers' perceptions of illegal marijuana cultivation on U.S. federal lands. Soc Natur Resour 29(2):185-202. https:// doi.org/10.1080/08941920.201 5.1062948
Sims H. 2016. Sheriff: Vicious dog attacks on livestock are 'result of illegal marijuana cultivation.'Lost Coast Outpost, Mar. 8. https://lostcoastoutpost. com/2016/mar/8/sheriffvicious-dog-attacks-livestockare-result-i/

Stansberry L. 2016a. Bye, bye night sky. North Coast Journal, June 2. www.northcoastjournal. com/humboldt/bye-bye-nightsky/Content?oid=3787331

Stansberry L. 2016b. Not even from around here: Who's afraid of the Bulgarians? North Coast Journal, Aug. 25. www.northcoastjournal. com/humboldt/noteven-from-around-here/ Content?oid=397074

Walker W. 2017. Guard dogs abandoned by migrant marijuana workers run wild in North Coast hills. KPIX 5, Feb. 10. https://sanfrancisco.cbslocal. com/2017/02/10/marijuanafarming-stray-dogs-humboldtcounty/

Wang IJ, Brenner JC, Butsic V. 2017. Cannabis, an emerging agricultural crop, leads to deforestation and fragmentation. Front Ecol Environ 15(9):495501. https://doi.org/10.1002/ fee. 1634 